Radiologe 2011 $\cdot 51: 169$

DOI 10.1007/s00117-011-2139-5

Online publiziert: 3. März 2011

(c) Springer-Verlag 2011

S. Delorme ${ }^{1} \cdot$ T. Helmberger $^{2} \cdot$ B. Stieltjes ${ }^{3}$

${ }^{1}$ Abt. E010 - Radiologie, Deutsches Krebsforschungszentrum (DKFZ), Heidelberg

${ }^{2}$ Institut für Diagnostische und Interventionelle Radiologie und Nuklearmedizin, Klinikum Bogenhausen, Städtisches Klinikum München

${ }^{3}$ Abt. Diagnostische und Interventionelle Radiologie, Radiologische Klinik, Universitätsklinikum Heidelberg

\title{
Diffusionsbildgebung im Einsatz
}

Sehr geehrte Leserinnen und Leser,

für den, der einen Hammer hat, sieht alles wie ein Nagel aus. Ein Hobby für MRNerds, kryptische Geheimwissenschaft, die Kunst, schlechte Bilder zu machen der Diffusionsbildgebung haftet so manches an. In der Tat mochte sich so rasch kein Kliniker für diese rauschigen Bilder begeistern. Doch welch ein Fortschritt: Früher allenfalls ein „add on" für die Schlaganfalldiagnostik, bietet „diffusionweighted imaging" (DWI) heute interpretierbare Bilder auch im Körperstamm. Ja, wir geben es zu: Auch wir mussten überzeugt werden, fragen aber heute immer wieder „wo ist die Diffusion?“

Trotzdem hüte man sich vor Vereinfachungen. Zunächst sind die Grundlagen hartes Brot. Der entsprechende Artikel von Laun et al. ist das Ergebnis langer Diskussionen zwischen Autor und Herausgeber (zwischen Physiker und Arzt), und, wirklich, einfacher geht es nun einmal nicht. Im Übrigen ist bei weitem noch nicht klar, was die Signale wirklich besagen, und in der Literatur geht es teilweise bunt durcheinander. Dabei gilt: Die Idee „hohe Zelldichte verringert Diffusion“ mag im Hirn funktionieren, woanders aber nicht. Zu komplex ist das Mikromilieu im Gewebe - Zelldichte, interstitieller Druck, Bindegewebe- und Fettkomponenten, Gefäßdichte und Perfusion. Alle sind mögliche Einflussfaktoren. Das heutige Heft bringt einen aktuellen Stand und zeigt, wo die Diffusions-MRT reif für den Einsatz ist und wertvolle Informationen bei der Gewebecharakterisierung lie- fern kann. Zugleich mahnt es zur Skepsis und vor Übereifer und zeigt Perspektiven auf. Sicherlich geht den Wissenschaftlern in diesem Gebiet der Stoff noch lange nicht aus.
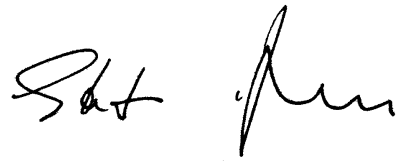

Prof. Dr. Stefan Delorme

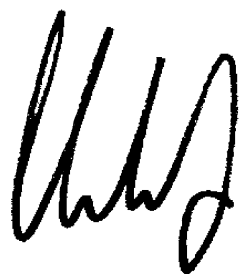

Prof. Dr. Thomas Helmberger

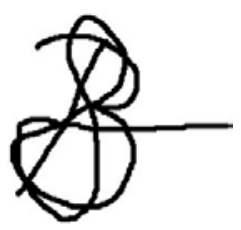

Dr. Bram Stieltjes 